\title{
ЭКСПЕРИМЕНТАЛЬНО-РАСЧЕТНОЕ ИССЛЕДОВАНИЕ ПАРОЖИДКОСТНОГО РАВНОВЕСИЯ В СИСТЕМАХ, ОБРАЗО- ВАННЫХ НАФТАЛИНОМ С ГОМОЛОГАМИ ИНДАНА ПРИ РАЗЛИЧНЫХ ДАВЛЕНИЯХ
}

\author{
(Представил О. Эйзен)
}

Решение проблемы выделения нафталина методом ректификации из нафталинсодержащих фракций тяжелой смолы пиролиза нефтяного сырья, прошедших гидрогенизационную очистку от ненасыщенных соединений, связано с исследованием диаграмм жидкость-пар в бинарных и многокомпонентных системах, образованных нафталином, инданом и его гомологами при атмосферном и пониженном давлениях.

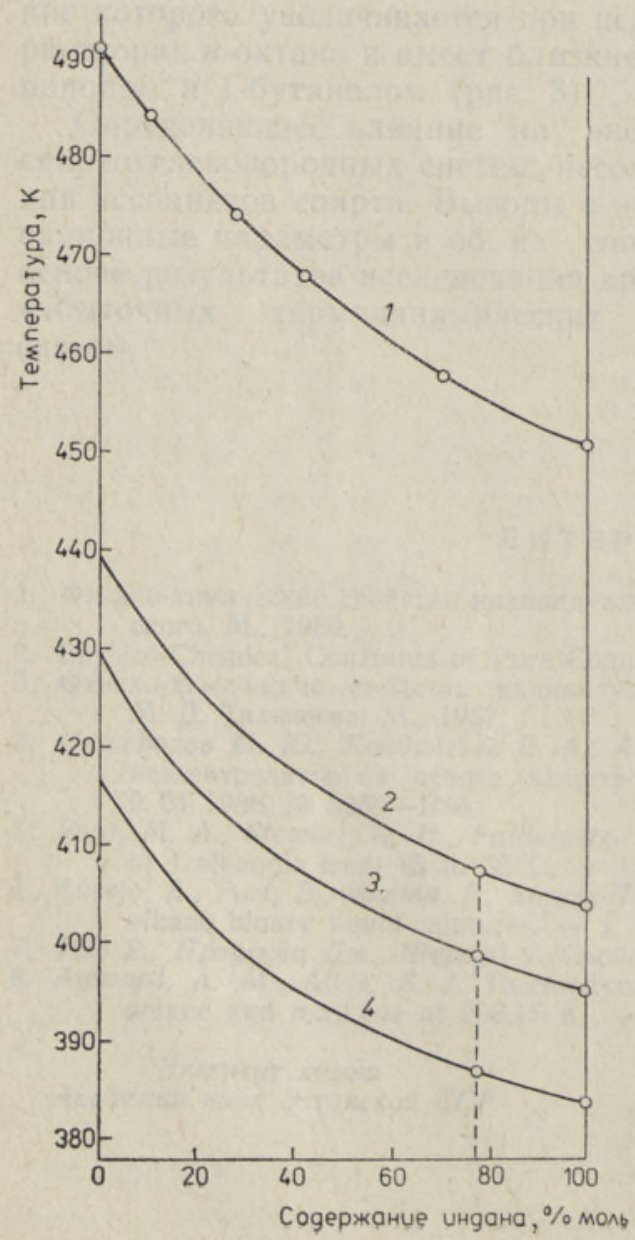

В настоящей работе экспериментально изучены зависимости температуры кипения от состава бинарной системы индан-нафталин при давлениях 101,$3 ; 26,66$; 19,$99 ; \quad 13,33$ кПа. Эксперимент проводился при атмосферном (эбуллиометр Уошборна) и пониженном (микроэбуллиометр Михкельсона [']) давлениях. Подготовка реактивов к эксперименту соответствовала требованиям, предъявляемым к чистоте веществ для эбуллиометрического анализа. Полученные данные приведены в табл. 1 и на рисунке. Зависимости, восстановленные по модели Вильсона, представлены в табл. 2. Можно констатировать, что система индан-нафталин зеотропна, имеет положительное отклонение от закона Рауля, при понижении давления неидеальность в системе незначительно возрастает.

Зависимость температуры кипения от состава системы индан-нафталин при давлениях 101,3 (1), 26,66 (2), 19,99 (3) и 13,33 кПа (4). Точки - экспернмент, кривые - расчет по модели UNIFAC. 
Экспериментально изученные зависимости температуры кипения от состава бинарной системы индан-нафталин

\begin{tabular}{|c|c|c|c|c|c|c|c|}
\hline \multicolumn{2}{|c|}{101,3 кПа } & \multicolumn{2}{|c|}{26,66 кПа } & \multicolumn{2}{|c|}{19,99 кПа } & \multicolumn{2}{|c|}{13,33 кПа } \\
\hline $\begin{array}{c}\text { содер- } \\
\text { жание } \\
\text { индана, } \\
\% \text { моль }\end{array}$ & $\begin{array}{l}\text { темпера- } \\
\text { тура, K }\end{array}$ & $\begin{array}{c}\text { содер- } \\
\text { жание } \\
\text { индана, } \\
\% \text { моль }\end{array}$ & $\begin{array}{l}\text { темпера- } \\
\text { тура, K }\end{array}$ & $\begin{array}{c}\text { содер- } \\
\text { жание } \\
\text { индана, } \\
\% \text { моль }\end{array}$ & $\begin{array}{c}\text { темпера- } \\
\text { тура, K }\end{array}$ & $\begin{array}{c}\text { содер- } \\
\text { жание } \\
\text { индана, } \\
\% \text { моль }\end{array}$ & $\begin{array}{l}\text { темпера- } \\
\text { тура, K }\end{array}$ \\
\hline $\begin{array}{r}0,0 \\
7,5 \\
28,1 \\
42,4 \\
69,9 \\
100,0\end{array}$ & $\begin{array}{l}491,16 \\
483,55 \\
474,16 \\
467,75 \\
457,76 \\
450,86\end{array}$ & $\begin{array}{r}0,0 \\
77,3 \\
100,0\end{array}$ & $\begin{array}{l}439,44 \\
407,94 \\
404,10\end{array}$ & $\begin{array}{r}0,0 \\
77,3 \\
100,0\end{array}$ & $\begin{array}{l}429,88 \\
399,09 \\
395,07\end{array}$ & $\begin{array}{r}0,0 \\
77,3 \\
100,0\end{array}$ & $\begin{array}{l}417,20 \\
387,47 \\
383,62\end{array}$ \\
\hline
\end{tabular}

Сравнение кривых на рисунке полностью (101,3 кПа) и неполностью $(26,66 ; 19,99 ; 13,33$ кПа) исследованных систем свидетельствует о хорошей сопоставимости полученных данных и возможности их использования для предсказания парожидкостного равновесия в системах нафталин-гомологи индана.

Матрица параметров энергетического взаимодействия (ПЭВ) групп $\mathrm{CH}_{2}, \mathrm{CH}_{3}, \mathrm{ACH}, \mathrm{AC} *$ модели UNIFAC представлена в табл. 3. В качестве базовых при расчете ПЭВ были взяты системы индан-нафталин и м-крезол-нафталин $\left[{ }^{2}\right]$ при 26,66 кПа. ПЭВ подбирали по методике $\left[{ }^{3}\right]$, Исходные ПЭВ брали из [ [ $]$. Работоспособность полученных ПЭВ проверяли посредством расчета парожидкостного равновесия системы инданнафталин при различных давлениях. Она показала (рисунок, табл. 2 II 4), что экспериментальные и расчетные данные имеют хорошую сходимость. Поэтому матрица применима для предсказания парожидкостного равновесия в ряду систем нафталин-гомологи индана при атмосферном и пониженном давлениях. В табл. 5 приведены константы уравнения Антуана для гомологов индана, восстановленные по температурам кипения из [ $\left.{ }^{5-7}\right]$.

В табл. 4 представлены коэффициенты активности изученных систем, полученные расчетным путем по модели UNIFAC (табл. 3). Неидеальность в системах нафталин-монометилинданы практически идентична (отличие в значениях $\gamma_{1}^{\infty}$ и $\gamma_{2}^{\infty}$ - в третьем знаке после запятой). Этот факт означает, что все монометилинданы, имеющие температуру кипения ниже температуры кипения нафталина, в модельных системах для расчета ректификации могут быть представлены одним компонентом с условной температурой кипения, которая выбирается в соответствии с соотношением метилинданов во фракции как аддитивная величина, и содержанием, равным суммарному содержанию монометилинданов. Аналогично, диметилинданы должны быть представлены в виде двух компонентов: 4,6-диметилиндана, температура кипения которого ниже, чем у нафталина, и условного компонента с суммарным содержанием 4,7-, 2,3- и 4,5-диметилинданов и температурой, рассчитанной по температурам кипения этих веществ.

Независимость $\gamma_{1}^{\infty}$ и $\gamma_{2}^{\infty}$ (табл. 4) от давления и температуры кипения переменного члена ряда (соответственно моно- или диметилиндана) обуславливает равенство констант уравнения Вильсона для систем нафталин-монометилинданы и нафталин-диметилинданы [ ${ }^{8}$. Указан-

* ПЭВ для группы АСОН, входящей в молекулу $\mu$-крезола, в настоящей работе опущены, 
Матрица параметров энергетического взаимодействия $a_{m n}, \mathbf{K}$

\begin{tabular}{|c|c|c|c|c|}
\hline Группы & $\mathrm{CH}_{2}$ & $\mathrm{CH}_{3}$ & $\mathrm{ACH}$ & $\mathrm{AC}$ \\
\hline $\begin{array}{l}\mathrm{CH}_{2} \\
\mathrm{CH}_{3} \\
\mathrm{ACH} \\
\mathrm{AC}\end{array}$ & $\begin{array}{c}0,0 \\
185,94 \\
-9,11 \\
-7,56\end{array}$ & $\begin{array}{r}141,67 \\
0,0 \\
173,90 \\
-178,08\end{array}$ & $\begin{array}{r}61,40 \\
3,43 \\
0,0 \\
-156,98\end{array}$ & $\begin{array}{r}211,55 \\
13,94 \\
-439,38 \\
0,0\end{array}$ \\
\hline
\end{tabular}

Таблица 4

Константы уравнения Вильсона и предельные коэффициенты активности в системах нафталин-гомологи индана

\begin{tabular}{|c|c|c|c|c|c|c|c|c|c|c|c|c|c|}
\hline \multicolumn{2}{|c|}{ Компоненты системы } & \multirow[t]{3}{*}{$\overline{\Lambda_{12}}$} & \multirow[t]{3}{*}{$\Lambda_{21}$} & \multicolumn{10}{|c|}{ Давление, кПа } \\
\hline \multirow[b]{2}{*}{1} & \multirow[b]{2}{*}{2} & & & \multicolumn{2}{|c|}{101,3} & \multicolumn{2}{|c|}{26,66} & \multicolumn{2}{|c|}{19,99} & \multicolumn{2}{|c|}{13,33} & \multicolumn{2}{|c|}{6,66} \\
\hline & & & & $\gamma_{1}^{\infty}$ & $\gamma_{2}^{\infty}$ & $\gamma_{1}^{\infty}$ & $\gamma_{2}^{\infty}$ & $\gamma_{1}^{\infty}$ & $\gamma_{2}^{\infty}$ & $\gamma_{1}^{\infty}$ & $\gamma_{2}^{\infty}$ & $\gamma_{1}^{\infty}$ & $\gamma_{2}^{\infty}$ \\
\hline
\end{tabular}

2-Метилиндан

1-Метилиндан

5-Метилиндан

4-Метилиндан

4,6-Диметилиндан-

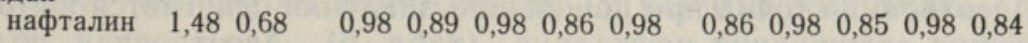

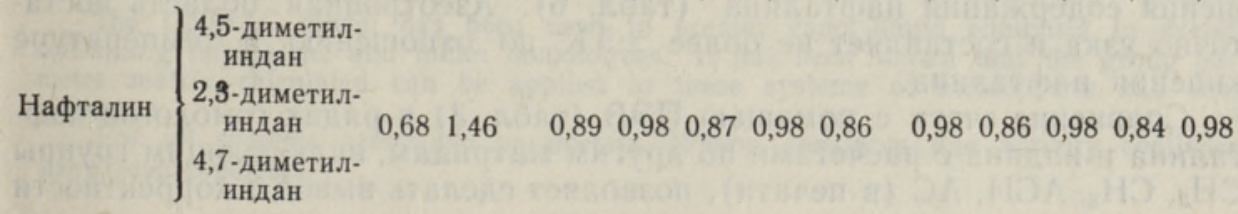

Константы уравнения Антуана $\lg P=A-\frac{B}{C+T}$

( $P-$ мм рт. ст., $\left.T-{ }^{\circ} \mathbf{C}\right)$

\begin{tabular}{l|c|c|c|c}
\hline \multirow{2}{*}{ Соединение } & \multirow{2}{*}{$\begin{array}{c}\text { Температура } \\
\text { кипения, K }\end{array}$} & $A$ & $B$ & $C$ \\
\cline { 4 - 6 } & & & \multicolumn{3}{|c}{ Константы } \\
\hline Нафталин & 491,21 & 7,1268 & 1828,04 & 212,53 \\
Индан & 451,26 & 6,7527 & 1402,22 & 183,97 \\
2-Метилиндан & 460,16 & 7,4551 & 1764,88 & 198,81 \\
1-Метилиндан & 462,16 & 7,4442 & 1776,18 & 200,20 \\
5-Метилиндан & 475,16 & 7,4369 & 1888,29 & 212,94 \\
4-Метилиндан & 478,68 & 7,4441 & 1926,59 & 217,17 \\
4,6-Диметилиндан & 485,16 & 6,8679 & 1575,12 & 183,14 \\
4,5-Диметилиндан & 493,16 & 6,5648 & 1396,95 & 159,09 \\
2,3 -Диметилиндан & 496,16 & 6,7666 & 1535,35 & 172,03 \\
4,7-Диметилиндан & 501,16 & 6,1617 & 1120,89 & 113,60
\end{tabular}


Азеотропные параметры изученных систем

\begin{tabular}{|c|c|c|c|c|c|c|c|c|}
\hline \multirow[b]{3}{*}{ Система } & \multicolumn{8}{|c|}{ Давление, кПа } \\
\hline & \multicolumn{2}{|c|}{101,3} & \multicolumn{2}{|c|}{26,66} & \multicolumn{2}{|c|}{19,99} & \multicolumn{2}{|c|}{6,66} \\
\hline & $\begin{array}{c}\text { содер- } \\
\text { жание } \\
\text { нафта- } \\
\text { лнна, } \\
\% \text { моль }\end{array}$ & $\begin{array}{l}\text { темпе- } \\
\text { paтypa, } \\
\mathrm{K}\end{array}$ & $\begin{array}{l}\text { содер- } \\
\text { жание } \\
\text { нафта- } \\
\text { лина, } \\
\% \text { моль }\end{array}$ & $\begin{array}{c}\text { темпе- } \\
\text { ратура, } \\
\mathrm{K}\end{array}$ & $\begin{array}{c}\text { содер- } \\
\text { жанне } \\
\text { нафта- } \\
\text { лина, } \\
\% \text { моль }\end{array}$ & $\begin{array}{c}\text { темпе- } \\
\text { ратура, } \\
\mathrm{K}\end{array}$ & $\begin{array}{c}\text { содер- } \\
\text { жание } \\
\text { нафта- } \\
\text { лина, } \\
\% \text { моль }\end{array}$ & $\begin{array}{c}\text { темпе- } \\
\text { ратура, } \\
\mathrm{K}\end{array}$ \\
\hline
\end{tabular}

Нафталин-

2,3-диметилиндан

Нафталин-

4,5-диметилиндан

$1,0 \quad 496,5$

20,0

493,5

16,0

441,9

Зеотропна

surasang

14,9


5. Свойства органических соединений. Справочник под ред. А. А. Потехина. Л., 1984.

6. Лин С. Т., Брюле М. Р., Янг Ф. К. Банк данных по синтетическим топливам. Нефть, газ и нефтехимия за рубежом, 1980, № 11, 138-144.

7. Anderson, $H$., $W u, W . R . K$. Properties of Compounds in Coal-Carbonization Products, Washington, 1967.

8. Miuahara, K., Sodotomo, H., Kitamura, K. Evaluation of the Wilson parameters by nomographs. - J. Chem. Eng. Jap., 1970, 3, N 2, 157-160. Уральский политехнический
институт

Институт химии

Академии наук Эстонской ССР

\section{Поступила в редакцию} 23/VI 1987

\section{G. LEHOVA, J. NOVIKOVA, M. GRINTSAK}

\section{AURU JA VEDELIKU TASAKAALU UURIMINE ERINEVATEL ROHKUDEL SUSTEEMIDES, MIS SISALDAVAD NAFTALIINI JA INDAANI HOMOLOOGE: EKSPERIMENT JA ARVUTUS}

Artiklis on esitatud keemistemperatuuri ja koostise eksperimentaalsed sōltuvused binaarses süsteemis indaan-naftaliin rõhkudel 101,$3 ; 26,66 ; 19,99$ ja $13,33 \mathrm{kPa}$. Auru ja vedeliku olekudiagrammid on arvutatud Wilsoni vôrrandi abil.

Rühmadele $\mathrm{CH}_{2}, \mathrm{CH}_{3}, \mathrm{ACH}$ ja AC on arvutatud energeetiliste vastastikmõjude parameetrite maatriks, mida kasutatakse auru ja vedeliku tasakaalu ennustamiseks rõhul $\leqslant 101,3 \mathrm{kPa}$ süsteemidele, mis sisaldavad naftaliini ja-indaani homolooge. On näidatud, et süsteemid naftaliin-2,3-dimetüülindaan ja naftaliin-4,5-dimetüülindaan on aseotroopsed (keemistemperatuuri maksimumiga); on arvutatud nende parameetrid.

\section{G. LEKHOVA, E. NOVIKOVA, M. GRINCHAK}

\section{CALCULATION OF VAPOR-LIQUID EQUILIBRIA IN SYSTEMS CONTAINING NAPHTALENE AND INDAN HOMOLOGUES AT VARIOUS PRESSURES}

The UNIFAC model has been used to predict vapor-liquid equilibria in systems containing naphtalene and indan homologues. It has been shown that the group parameter matrix calculated can be applied to these systems at atmospheric and lower
pressures. For all systems azeotropic parameters, Wilson constants and activity coefficients
have been predicted. 